\title{
REGENERATING PLACES SUSTAINABLY: THE HEALTHY URBAN DESIGN
}

\author{
MARICHELA SEPE \\ IRISS National Research Council-DIARC, University of Naples Federico II, Italy.
}

\begin{abstract}
Current needs of people are continuously changing due to the rapid transformation of territories, which present more and more social, virtual, environmental and urban infrastructures, which are intersected and overlapped in different and not always sustainable manner. However, some points seem to be important for the well-being of people and sustainability of places. For these reasons, the needs of more healthy, happy and liveable places are increasing, and the studies on these fields are becoming always more important to identify both the intangible and tangible aspects capable of giving a scientific point of view on the above topics. If from a part many indexes have been created, from the other these change continuously and are created with different parameters, which can sometimes give rise to a nonunivocal interpretation. Furthermore, many studies are focused only on one aspect capable of giving health, happiness and liveability and do not consider the intangible aspects suitably. The most happiest city or the most liveable place or, again, the city which is considered the healthiest are data which are more and more used to increase attractiveness and competitiveness to an area of transformation or a whole city. The use of a correct method to collect and use these data suitably is currently a need to obtain a sustainability meant in the threefold meaning, namely, social, environmental and economic one. Starting from these premises, the aim of this study is to present the main research on these topics and illustrate the original Ecoliv@ble+ design method, which was created in order to identify urban health, liveability and happiness from the users' point of view and identify sustainable design interventions to enhance or create these factors. The emblematic case of False Creek area in Vancouver, British Columbia, interested by a long process of urban regeneration, and relative observation on the method conclude the article.
\end{abstract}

Keywords: liveability, place identity, public space, sustainable urban regeneration, urban design, urban happiness, urban health.

\section{INTRODUCTION: THE ROLE OF HEALTHY IN SUSTAINABLE URBAN DESIGN}

Current territories are characterized by an overlapping of always more urban, natural and virtual elements.

Environmental disasters, social and economic crises, the development of new technologies, lead to new cities and new ways to mean borders and connections. Contemporaneously, the increasing loss of meaning of place as a recipient of social customs, historical memories and symbolic contents has led to the emergence of places with provisional uses, linked to a contemporaneity, which cares more about satisfying immediate consumption than sedimenting traces of culture [1-8].

As a result, current needs of people are more difficult to identify and then to design. But, although people need change continuously, some important factors remain points of reference for urban planners who pay attention to design places for people. Accordingly, well-being and healthy — even though defined in different manner - are a priority [9-15].

Furthermore, the metropolitan cities have changed administrative and legislative borders of territories, transforming or trying to transform them in wider and better connected areas, putting together both intangible and tangible, landscape and urban resources.

Among the new borders, connections and interrelations, there exist new public spaces, which in different manner act as collectors and facilitators of relationships among places, 
people and memories. In the contemporary city, in parallel with the traditional places of socialization (squares, main streets, etc.), there have arisen urban structures which vary in size, quality and shape but have in common the aim of favouring a prolonged use substitutive of that of public spaces.

However, for the socialization and integration of people, the public space covers a very important function in the framework of the urban territories and, for this reason, its quality is an important factor in the construction, reconstruction and enhancement of a sustainable place, where sustainability is meant in its threefold meaning, namely social, economic and environmental.

At the same time, also the demands of visitors are more and more changing. The development of both the Internet and social networks, the low-cost transport rates, the companies to rent rooms and hotels at increasingly competitive prices have meant that visitors can organize their journey in the manner most appropriate to them and choose the destination also being guided by reviews, photos and films on the network. In addition, there is a general tendency to travel more frequently and for fewer days and, consequently, to travel at different times of the year.

Demand, in terms of tastes, has become increasingly diversified, also requiring an adjustment by the supply. The demand ranges from ecological tourism to food and wine, from cultural to religious, from congress to sports, spa and wellness, just to name a few, and each of these themes has many other specific and multiple needs due to different age and family household.

In line with these ideas, the relationship between health, liveability, happiness and urban design is the complex result of multiple elements, which play different roles in the city system. Improving these factors with sustainable urban design, and preserving place identity as well, is a great challenge. To suitably understand this complex system, the topics are firstly illustrated separately.

With respect to the health theme-which is strongly connected with liveability and happiness-, recent studies [16] report that firstly it is important to identify reasons why people who live in cities have greater risk to have health problems because of different factors. These include: disparities, crowding, noise and pollution, which can produce stress and encourage people in avoiding social relationships that are important for mental well-being; low presence of green, possible reduction of leisure time, security and privacy.

Urban design and planning can contribute to decreased mental health problems and improved happiness in the city by reducing those risk factors. The Mind the Gaps frameworks created by McCay [16] identify four topics to make tangible the urban planner help, even though not even one city still embodies all of them. Topic 1 is, as affirmed in different theories, access to urban green places, which can have many good factors including encouraging exercise and social interaction; Wilson affirms that the good effect of green space stands in the fact that humans have biological need satisfied by the contact with other species; Ulrich states that the good effect is due to the contemporaneity of experience with aesthetics of nature and distance from everyday problems; the Kaplan (Rachel and Stephen) theory proposes that natural sites draw the attention of people more than the non-natural because these last need contemporary concentration on many elements.

These theories can help us understand the positive effect of green space in mental health but are not enough to assume that the design of green space in a site can assure improvement in mental health. There are other factors which can influence negatively in green space such as inaccessibility, bad management, a feeling of threatening that can discourage its use. Green 
spaces should be designed to be welcoming to different kinds of people and not monopolized by certain groups. Indeed in some cases, green spaces can encourage behaviours, which are anti-social and discourage their use, because people feel unsafe in those spaces.

Successful green spaces should be walkable and be suitable for both physical and visual accessibility, which improve people's well-being. Accordingly, small presence of green in small space, streets or workplace is important as well.

Another important factor is to create different options of transport such as paths for pedestrians and for bikes, which help reduce sedentary habits.

Furthermore, it is important to design public spaces with flexible use, which are capable to create a sense of belongingness and community, providing street furniture for both resting and chatting and other elements, which contribute to social activities and the general perception of well-being.

The perception of safety also contributes to a better quality of life and public spaces, and those that are capable of contributing to this feeling are successful. Some features, which can help this feeling, include suitable lighting and clear landmarks.

As Saunders [15] affirms people in the last decades are living longer than ever and so it is necessary to have healthier places to allow healthier life to all. This is because the daily activities such as work, travel and leisure are directly or indirectly connected to the place where these occur requiring suitable spaces. Elements such as air pollution, noise, road dangers and social connectedness can influence our health in different ways. The question is to understand what of these factors influence health and how to address them. Saunders suggests to address all of them at once and implementing good practice in urban design at the largest possible scale.

Indeed, places which are good for people are often healthy as well. In public realm, this often means the diminishing in motorized transport, which is used for carrying people who could instead walk or cycle. Motorized transport impacts in non-positive ways on air pollution and physical inactivity, transforming public spaces in noisy and unwelcoming areas. And these also increase the problems deriving by poor access and road danger, which are particularly important for the most disadvantaged people. Putting people at the centre of the urban design and decision potentially reduces the inequalities. Accordingly, Healthy streets, as Saunders suggests, identify 10 indicators, which indicate how to design urban spaces and transport policies which make people first [15].

The most two important indicators-pedestrians from all walks of life and people choose to walk and cycle - have the aim to create places in which all people can participate in public life and both healthy and friendly environment design are considered in priority way.

The other eight indicators - people feel relaxed, easy to cross, clean air, not too noisy, places to stop and rest, people feel safe, things to see and do, shade and shelter show-clarify what is necessary to do to create inclusive, appealing and healthy places. Places, which do not have these characteristics, discourage people using them. All professionals - transport professionals, landscape architects, community groups, artists, planners and developers-are involved in the realization of Healthy streets and all the indicators are necessary for creating them.

A big challenge is to meet the demands of the different stakeholders in order to put in practice the principles, all often in limited spaces. Every street requires different approach according with social, physical, political or financial questions, which can weight in the general design not always in the same way. The important, as declared by Saunders, is that the general objective is to create public space which works better for people and are healthy and liveable for all. 
Although there is recognition of the importance of liveable public spaces for keeping people in good health, it is difficult to demonstrate that good urban design is capable of reducing, for example, heart disease. The increase in the number of people who spend time, walk and cycle on the streets can be shown easily, and this is the first measure to demonstrate the success of the environment from health point of view.

Furthermore, there exist important factors which create good interactions between places with behaviours, including: the promotion of daily activities such as walking or cycling, which help people in having a healthy weight; the facilitation of easy access to healthy food and the promotion of connected neighbourhoods and economic development.

Finally, the Crappsley's [17] approach to healthy design is mainly focused on streets and includes: reducing on-street parking and reallocating road space for vehicles, while adding space for walking and cycling; improving both the quality of footway zones and furniture and making easier for all age people to cross the streets; making bicycle infrastructures safer and more comfortable, introducing suitable separation with busy roads; slowing traffic, using different kinds of visual elements and tight corners; improving environmental elements, such as trees, sustainable drainage, shades streets and reduction of traffic noise; adding on-street activities with both formal and informal activities which encourage people to use the space for social interaction or spend more time there; making safer the streets dissuading crimes and sense of insecurity, improving suitable lighting, natural surveillance; and making streets welcoming for all, improving accessibility.

Healthy and liveable urban designs are capable of influencing urban happiness in many ways, contributing to sustainability and the preservation of place identity.

Starting from these theoretical premises, this work will discuss about the original Ecoliv@ ble+ design method in Section 2, the emblematic case study of False Creek area of Vancouver in Section 3 and conclusions in Section 4. The method-and the case study-is carried out in the framework of the IRISS CNR research project 'Contemporary urban landscape design: place identity, happiness, liveability, health and sustainability' (with the author's responsibility).

\section{MAPPING HAPPINESS, DESIGNING HEALTH: METHOD AND OBSERVATION}

The present study on these topics [18-26] together with the previous consideration has led the author to create Ecoliv@ ble+ design method. This is constituted by both a rigid and flexible protocol, capable ofidentifying urban health, liveability and happiness, and the factors which make places healthy, happy and liveable from the users' point of view. The method comprises 5 parts of analysis, which consists of different kinds of surveys, observations and questionnaires and three phases of design, which include the check of consistency with the 25 principles of the Charter of urban health, liveable and happy urban design.

The Ecoliv@ ble+ design method (Table 1) is an evolution of both the original PlaceMaker method [6], devoted to the identification of elements which constitutes the place identity and intervention for its enhancements, and the Ecoliv@ble+ design method [2], devoted to identification and design of the factors capable which give happiness to people who use the places.

Phase 1 of the method is devoted to the identification of the area to analyse. This phase is quite difficult because the borders of the area are decided on the bases of the continuity of the identity of the space and this is not always evident. The study area is decided after one or more inspections and can be modified if, during the surveys of the other phases, it is observed that other parts of the space too are important to add. 
Table 1: Ecoliv@ ble+ design method.

\begin{tabular}{|c|c|c|c|}
\hline Phase & Objective & Actions & Product \\
\hline 1 & Definition of the area & Visits on site & $\begin{array}{l}\text { Map with the definition } \\
\text { of the borders }\end{array}$ \\
\hline 2 & $\begin{array}{l}\text { Observation of character- } \\
\text { istics of the place }\end{array}$ & $\begin{array}{l}\text { Surveys of people activi- } \\
\text { ties perceptions (singu- } \\
\text { lar and mixed) elements }\end{array}$ & $\begin{array}{l}\text { Map of characteristics of } \\
\text { the place }\end{array}$ \\
\hline 3 & $\begin{array}{l}\text { Questionnaire to place } \\
\text { users }\end{array}$ & $\begin{array}{l}\text { Identification of ele- } \\
\text { ments which make that } \\
\text { place healthy, liveable } \\
\text { and happy from people } \\
\text { point of view }\end{array}$ & Mosaic of users ideas \\
\hline 4 & Analysis of cartography & $\begin{array}{l}\text { Identification of ele- } \\
\text { ments that compose the } \\
\text { place }\end{array}$ & $\begin{array}{l}\text { Map of the traditional } \\
\text { elements which compose } \\
\text { the place }\end{array}$ \\
\hline 5 & $\begin{array}{l}\text { Identification of factors } \\
\text { of urban healthy, liveabil- } \\
\text { ity and happiness }\end{array}$ & $\begin{array}{l}\text { Overlapping of all data } \\
\text { collected }\end{array}$ & $\begin{array}{l}\text { Map of urban healthy, } \\
\text { liveability and happiness }\end{array}$ \\
\hline 6 & $\begin{array}{l}\text { Check of the degree of } \\
\text { healthy, liveability and } \\
\text { happiness }\end{array}$ & $\begin{array}{l}\text { Overlapping between } \\
\text { the map of urban } \\
\text { healthy, liveability and } \\
\text { happiness and the } 25 \\
\text { principles of the Charter } \\
\text { of UHLH }\end{array}$ & $\begin{array}{l}\text { Map of the areas to be } \\
\text { improved }\end{array}$ \\
\hline 7 & $\begin{array}{l}\text { Check of the design ideas } \\
\text { with the users of the } \\
\text { place }\end{array}$ & $\begin{array}{l}\text { On-site questionnaire } \\
\text { and research on the } \\
\text { websites with the user } \\
\text { requests }\end{array}$ & $\begin{array}{l}\text { Mosaic of degree of plea- } \\
\text { sure on the design ideas }\end{array}$ \\
\hline 8 & $\begin{array}{l}\text { Identification of project } \\
\text { interventions for the } \\
\text { realization of the Charter } \\
\text { principles }\end{array}$ & $\begin{array}{l}\text { Overlapping of all data } \\
\text { collected }\end{array}$ & $\begin{array}{l}\text { Map of urban health, } \\
\text { liveability and happiness } \\
\text { design }\end{array}$ \\
\hline
\end{tabular}

Phase 2 is that of the surveys on the place to collect the perceptions, the kinds of activities and the elements that contribute to the perception of urban happiness, health and liveability. Accordingly, three surveys are carried out during a weekday, a weekend day and during particular festivity of the area. The hours of the surveys are important as well: the morning and the afternoon period of the day are often very different for the observations and both important. In some specific area also the evening inspections are necessary, but usually the daily and afternoon hours are sufficient to understand the use of the place. The first survey is devoted to the observation of the activities that are carried out on the area study, the kind of people who make these activities, the frequency (low, medium or high) and the pace (slow, moderate or hectic). The activities which can be done in a public space are many, namely walking, cycling, resting, watching, running, 
observing and so on. As regards, it has to be observed the kind and age of people who use the space in object, namely residents, locals, professionals, tourists, children, middle age persons, elderly and young. Then it is important to identify who does what and with what frequency and pace. All these have to be measured from quantitative point of view, namely: low, medium and high with respect to both the frequency and people; rapid, slow or moderate with respect to the pace. The quantitative measure of the elements in the different days and hours gives the qualitative sketch of the pleasure of the space. The more the surveys are accurate the more the results are useful to the understanding of the use of the area.

The second survey is that of the perception both singular and mixed. This is a not simple survey because it must separate the singular perception and then merge. The first operationto separate the singular visual, taste, tactile, smell, acoustic perceptions-is difficult because usually the perception which is felt is the visual one and the others are less considered. On the contrary, we feel a place with all the five senses and each of that is necessary for the perception of the space. The mixed perceptions are given by the union of two or more singular perceptions, namely it is possible to observe the chaos or the calmness, the serenity, disorder, disorientation, joy, harmony, disorientation and so on. All the perceptions have to be measured from both the quantitative point of view_low, medium and high — and from the qualitative one-non-influential, pleasant and annoying.

Then, the survey 3 has to be carried out. This concerns the kind of elements, which contribute to the perception of happiness, healthy or liveability of the area. These can regard the constructed and natural elements, furniture of different kinds, pavement, benches, playground, pedestrian and cycling area, fountain with potable water and so on. The presence of these elements has to be surveyed with respect both to the quantity and the quality, expressed as low, medium and high.

To collect all the elements, a suitable database has to be used which is capable to support the collection of data suitably. A photo and video survey can be added to take notes and reobserve the activities, which are done on the area. After the three surveys, an overlapping of all the information is carried out to comprehend the presence and degree of healthy, happiness and liveability on the case area. Not always all these three factors are present and not in all the area. It is important to accurately identify space, kinds of people, activities and elements, which contribute to the factors which are useful for the analysis.

The next phase-phase 3-concerns the perception of happiness, health and liveability by who is not involved in the study but perceive the place as a visitor, a resident, a local and so on. The professionals, in general, interpret the place with an already 'pre-formed idea', while a common user gives a comment with no prefigured scheme.

To realize this phase, a questionnaire is administered to people during a weekday, a weekend day and during particular festivity of the area and in the 2-h period of day, namely in the morning and in the afternoon. The specific hours of the day depends on the period of the year, which can determine a more or less use of the place because of the presence or absence of the natural light.

The questions are, in general, similar for all the place, but can vary according to specific objective of the case study or the area. Some of this include: What are the activities that you act in this place and how often? This place gives you a feeling of happiness or sadness/liveability or discomfort/health or unhealthy? According to the current place healthy, liveability and happiness what could be done in order to improve this place?

Answers by people can be very different above all with respect to the age or the possibility to enjoy of all the furniture and facility of the place. And, again, some answers could be not 
useful for the study, so it is important to reformulate the question in another way in order to obtain a useful data. Furthermore, it is important to choose the right part of the space to administer the questions, because not all the people are available-for time and other reasons-to answer.

Phase 4 is the phase in which the study of the cartography is carried out in a traditional way, namely collecting the information which the planimetry of the place is capable to give to the observer. No further information have to be included, such as the perceptive ones, because these are collected in the previous survey on-site. The study can be done using two kinds of materials. The first concerns the urban planning or design projects, which are realized there or have to be carried out. Then, there is the study on the planimetry, which gives as a result the identification of all the elements which constitute the area from both the history and the urban point of view, namely: the identification of the urban fabric, the historical buildings, the axis, the main streets, the green, the sea, the hill and so on. Often the inspections on the place to survey the activities and perceptions not allow to well understand the urban composition of the area which, instead, can be realized in this phase.

The last phase of the analysis - phase 5-is that of the overlapping of all the elements and observation carried out in the previous phases. This phase gives a mosaic of data to identify if health, happiness and liveability are in present place and the factors that contribute to this perception. This phase is fundamental in this method because it allows us to put together the different data collected in an only one scheme or map which comprehends results of the surveys, questionnaire and traditional analysis.

From now on, the parts of design start. Phase 6 of the method is devoted to identify the current degree of health, liveability and happiness through the observation of both intrinsic and extrinsic factors contained in the mosaic-map: perceptions, tradition and culture concern the intrinsic factors; architecture, facilities and urban furniture concern the extrinsic factors. The areas with a minor presence of health, liveability and happiness or which are underused with respect to the place, in general, are in this way identified and represent the areas where the project interventions have to be concentrated. These can include: empty spaces, non-utilized squares or areas destroyed following an environmental disaster.

The check is carried out through the principles of urban health, liveable and happy design concerning the aforementioned Charter. The principles are 25 and include: to promote sculptures, games or other elements and amenities which can bring a smile to a person's face, promoting a state of liveability and happiness; to promote the educational function, which a place has,for example, clearly displayed information about history of the place, and so on or suitable ways to use it-increasing its intrinsic value; to encourage the use of the place by people of different age groups, from children to the elderly; to facilitate the use of new technologies to increase the knowledge of its intangible values and history, offering a more profound experience of the place; to improve suitable pedestrian and cycle lines; to eliminate architectural barriers, which might discourage people from frequenting that space; to retain an adequate state of cleanliness and maintenance; to have the presence of water in different shapes (e.g. fountains) which promotes the vitality of the place; to encourage the presence of art in its different forms; to create a suitable balance between the elements of nature, landscape and equipment in the composition elements of the space; To both allow and promote different types of functions such as games, breaks, walking, etc.; to create suitable spaces for dogs and domestic animals, which are accompanied by their owners; to have both in streets and in public spaces natural lighting during the day and artificial at other times, avoiding artificial light in day hours; to have the possibility of doing actions - such as walking, watching, etc.- - in a moderate or slow pace, promoting opportunities to take breaks in the space; to 
create a sense of security and safety to those who walk, cross, rest and do different activities in the public spaces; to minimize or eliminate the noise generated by public transport; to fully perceive naturally occurring smells - for example, wood, grass, sea, etc. to have the possibility of using the space in different weather conditions and seasons, contributing at the same time to its continuous good state of maintenance; to have direct contact with natural materials, preferably local, used in the design of the space; to promote participation, namely the feeling of being able to contribute to the life of that place, increasing the sense of belongingness; to have the possibility of doing actions that normally are not permitted - such as walking barefoot in the water or in the designated public areas -, improving a feeling of freedom and joy; to encourage the consideration of the place as symbolic of the neighbourhood, improving the perception of its identity; to facilitate gymnastic activities-also slow ones-with a small equipment or a designated space; to preserve both the place identity and the intangible characteristics of the site and its surroundings; a healthy, liveable and happy place is a space that can transmit feelings of health, liveability and happiness to everyone who uses it. If all the principles are respected it is not useful to make the other phases of the method, because the area is healthy, happy and liveable as it stands.

Phase 7 is the participation to the first ideas of design emerged with the users of the place in order to obtain a mosaic of degree of pleasure on these. The questionnaire can be carried out on-site and online. The on-site questionnaire is similar to the previous one and consists in administering to people what they think about the main design ideas that resulted by the collected data. This is, as the previous, an important moment of participation, capable of giving us the measure of the degree of pleasure of the idea of transformation of the area. The information collected online concerned the booking website and the social networks where it is possible to understand if and how the place is used and what is the degree of satisfaction.

The number of likes, followers of Instagram, Facebook and Twitter page-where present - and so on are data to be collected. By the overlapping of both the way to collect the data, it will be possible to obtain the degree of pleasure of the design idea. The integration of all these data is quite difficult: the comments on the social networks and booking websites can report information which are different from the results of the on-site questionnaire; the hashtags can be related only to one aspect which is interesting for the study. An accurate overlapping of all the information has to be done in order to obtain the right result.

Phase 8 consists in the identification of design interventions to make the area healthy, happy and liveable. The design interventions have to be identified according to the different spaces of the area and can be accompanied by sketches and drawings to visualize the ideas.

The project design interventions starting from the results which were obtained from the method could be more than one. The important is keeping in mind that the main aim is to design a sustainable place focused on health, happiness and liveability.

\section{THE CASE STUDY}

The Ecoliv@ble+ design method aims-with different kinds of surveys, observations and questionnaire - at identifying sustainable urban liveability and the factors which make places happy, liveable and healthy from the users point of view; identifying design interventions to enhance or create both urban liveability and health.

The case study which will be illustrated in synthesis in the following is constituted by the new area of False Creek (Fig. 1) in Vancouver in the British Columbia province of Canada.

This area contains many elements of interest including the presence of public spaces, playground, monuments, waterfront, panoramas, mixed use and many activities for free time. 

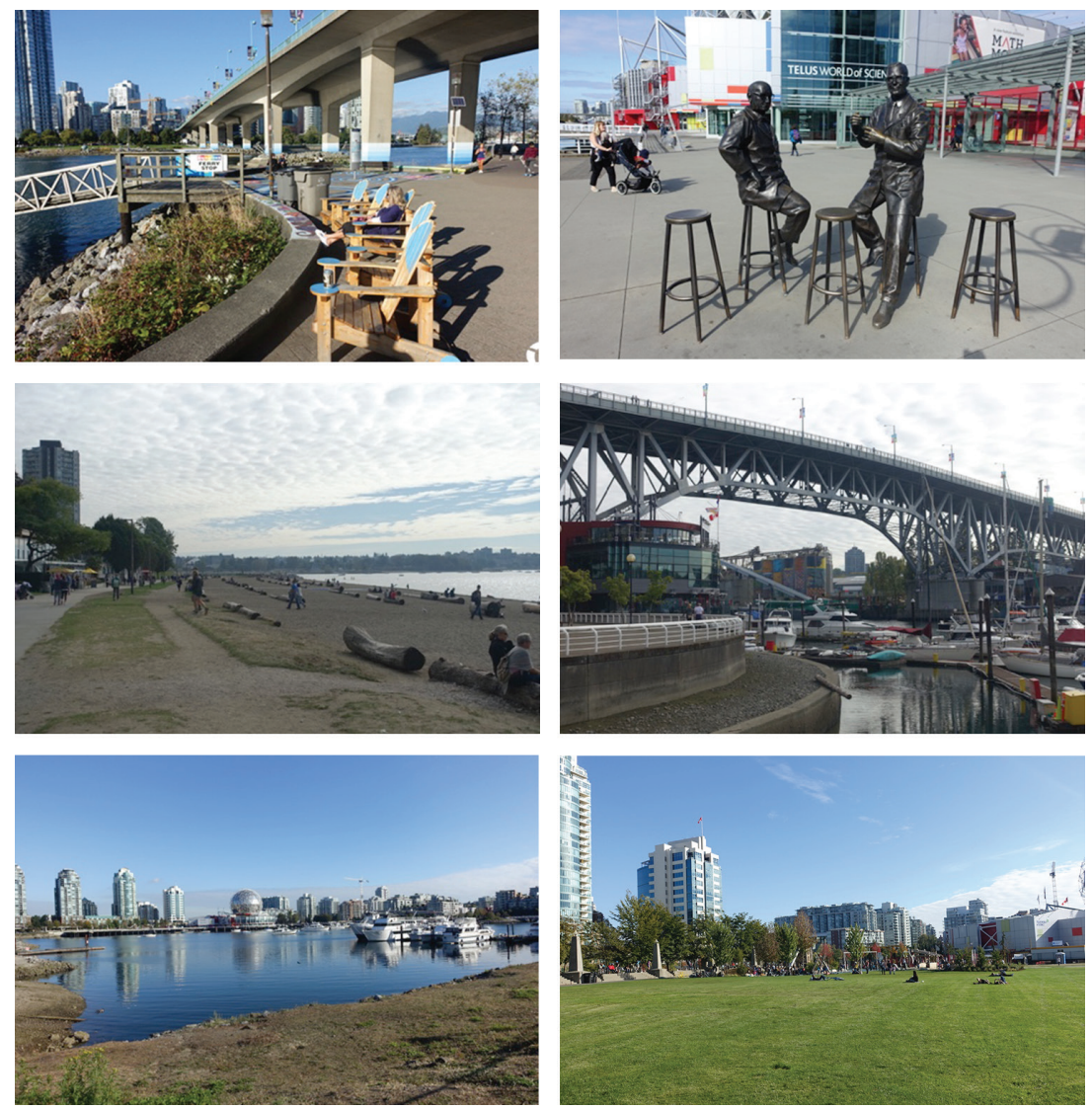

Figure 1: False Creek, Vancouver, images of the area.

Source: photo by the Author.

As regards the first phase of the Ecoliv@ ble+ design method, with the on-site visits it has been decided on the borders of the area. False creek is the area delimited by the Science World British Columbia and English Bay. After the on-site visits, it was decided that the study area is all the body of water included between Burrard Street Bridge and Quebec Street. The waterfront area concerning False Creek basin is mostly a pedestrian area. Observations were carried out both during the week and week end days; the data which were collected are interpreted as follows.

The activities (phase 2 of the method) are many and different due to the extension of the place and the existence of many functions. The area-to both better collect the data and illustrate the results-was divided in three parts, namely, North, South and Olympic village.

The South walking route stands along the seawall from the Cambie Street Bridge and the Granville Street Bridge, the North part is on the opposite site between Burrard Street and Cambie Street. The Olympic village is between Cambie Street and Quebec Street. In the North area, the activities include: walking, cycling, running, resting, watching the panorama, eating, parking and taking yachts or ferries that are shuttling to and fro and taking photos and selfies, all done with high frequency in a moderate pace by the people who use this place. 
In the South area, the activities include walking, cycling, running, resting, eating, going to Granville Island and taking the shuttling ferries. These activities are carried out with high frequency by people who use this place in a moderate pace. Other activities include going to the gym, bringing the babies to walking with the stroller, watching the panorama, taking photos which are carried out with medium to high frequency and mainly in a moderate pace.

In the Olympic village, the activities include: visiting the Science World Museum, visiting the Village, walking, cycling, running, resting and playing in the playground. These activities are carried out with medium to high frequency and in a moderate pace by people of different ages.

Pleasant perceptions are, in particular, visual, touch and smell, due to the panorama and views on both the basin, the presence of sand, grass with trees and flowers, the well-maintained and comfortable floor. In Granville Island, the perceptions include the taste as well as smell due to the various particular food products that are in the market.

Mixed perceptions are related to the fact that the places are of very good quality design, and materials and the spaces that are devoted to all of the activities are suitable. Then, the mixed perceptions include health, liveability and happiness. In many parts of False Creek, there are sculptures of different types, which improve the perception of happiness often connected to the art. Furthermore, this area gives a perception of safety.

People who use this place-because of the presence of many activities and facilities-are mainly locals, residents, professionals and visitors of all ages. Furthermore, in this area people with disabilities have comfortable or dedicated paths.

Answers (phase 3 of the method) by people-about 100 administered in English language to locals, residents, visitors and professionals-were quite similar with respect to the perception of happiness, liveability and health given by this place.

To the first question: this place gives you a feeling of happiness or sadness/liveability or discomfort/health or unhealthy_about $100 \%$ the people answered that the place gives positive feelings such as of happiness, liveability and health.

To the question, what are the elements that give you the above sensations?, answers covered different ideas of the place, due to the many functions which are present there. $60 \%$ of people — both locals and tourists — answered that they are surprised by the beauty of the panorama and the comfort of the streets; $30 \%$ of people-mainly locals - answered that they like the possibility to do many kinds of things and use the area at different hours of the day and under different weather conditions.

To the question, what are the main facilities that give quality to this place? $70 \%$ of people—both locals and visitors - answered that there are lines dedicated for walking, running, cycling and skating, often in both directions. Of this, $30 \%$ of people added that this represents an important factor for safety and comfort. The other $30 \%$ answered different facilities including bar and restaurants, and then benches, playgrounds, open air gym furniture and a museum.

To the fourth question, what are the activities that you act in this place and how often?, $65 \%$ of people — both locals and visitors - answered that they walk, take a break, ride a bicycle or run. The remaining 35\% make different activities including-for locals_-bringing the children to the playground or the parent with the wheel chair, going to the Granville marketto buy food or objects - go to the museum, take their boat, take the shuttle boat, or go to the restaurant, pub etc. in the area, for both locals and visitors.

To the question, what do you think about the presence of many or few people here?, $100 \%$ of both locals and visitors answered that the presence of many people give to the place a good atmosphere of liveability and pleasantness of the places. 
To the question, according to the current place health, liveability and happiness what could be done in order to improve this place?, $85 \%$ of people answered that to improve the liveability of the place, some parts have to be included and $15 \%$ answered that the place is suitable as it stands. $100 \%$ of people in general answered that the place is full of green and open air activities to do, making it very healthy. Of this, $20 \%$ of respondents added that some views are very beautiful and give the perception of joy; these include the sea, the mountains and the Vancouver skyline.

To the seventh question, what is a healthy/happy/liveable place that you remember in this city or elsewhere?, all the locals answered some other place of Vancouver including Coal Harbour and Capilano. 100\% of visitors, in general, answered that this place is quite unique because of the presence of many activities and the perception of liveability.

Finally, to the question, how the weather condition might influence the perception of liveability or happiness in this place?, $100 \%$ of respondents-both locals and visitorsanswered that when the weather is too cold, the open places are less liveable, but there are many restaurants and pubs, Granville island and a lot other sites in the area where it is possible to stay to enjoy the views or to spend time.

Information collected by the internet websites such as Tripadvisor-with about 56,000 positive comments on this place and its attractions - or booking - with hundreds of positive comments on panorama, walkability, cyclability and the general beauty of these sites-are in line with the on-site questionnaire even though less specific with respect to the perceptions and information such as the frequency of the activities which were carried out.

Furthermore, a social network research was carried out to understand the presence of this place and the degree of people satisfaction. The Instagram profiles include: False Creek Community Centre, Southeast False Creek Living and False Creek Ferries, with 1195 followers. Hashtags include: \#falsecreekferries \#falsecreekseawall \#falsecreekvancouver and \#falsecreek with 125k posts. The twitter profiles include: @FalseCreekRes; @ sefalsecreek and @FalseCreekFerry with 2.812 followers. Facebook profiles include False Creek Community Centre; False Creek Residents Association and False Creek Co-op and Creekside Community Recreation Centre, with 1209 followers. All these information and the thousands of likes on the posts confirm the liveability and the success of False Creek.

As regards the traditional analysis, False Creek is an inlet located in downtown Vancouver and is accessible by public transportation or by car. It is easily accessible for pedestrians as well. It is possible to take a little boat to cross some parts of the area.

Through to the 1950s, the False Creek area was the industrial heartland of Vancouver with sawmills and small port operations. After some years, the area was subjected to deterioration due to the change of the industry towards other areas. In 1960, the area was ingested by a large fire which destroyed all the parts of facility. Then, the future of False Creeks was constructed upon different debates concerning the urban renewal. At the beginning, there was little consultation of people, but from 1968 a major public involvement started and it was established to create an accessible waterfront with mixed-tenure housing and live-aboard marinas, a vibrant waterfront market, a wide park, communities centres and street front shops and services. In 1998, Vancouver City Council adopted a set of Blueways policies and guidelines including the vision of a waterfront city which has to meet the environmental, cultural and economic needs of the City with sustainable, equitable and high quality actions for people. In 2010, the Olympic Village, for athlete housing and logistics of the Winter Olympics, was found in Southeast False Creek, forecasting the development into a residential area with housing and services for about 11,000-13,000 people [27,28]. 
The current length of the entire seawall is $22-\mathrm{km}$ along with the area that presents streets for pedestrians and cycle lanes in two directions. The most important buildings include the Science World and the city's central stadium [27,28].

The main factors which are reported in the phase 5 of the method-the map of urban health, liveability and happiness - are constituted by: the general variety and beauty of the area which include both natural and constructed parts; the park; the high quality street furniture, the perception of safety, the playgrounds, the presence of the Granville market with different activities and products, good accessibility, a wide and liveable waterfront, the views on the sea, the skyscrapers, the bridges and the mountain.

By checking the consistence between the results of different surveys and the Charter of 25 principles, also in this case urban health, liveability and happiness were generally observed. In False Creek-for this reason-the phases of design were not necessary.

\section{CONCLUSION}

The urban condition of today shows many changes in terms of the rhythms and exploitation of the city, the modalities of living, working, moving around and the opportunities for enjoying leisure. The emergence of new typologies of place and changes in the patterns of usage for the existing typologies have given rise to whole new cityscapes. Striking juxtapositions and fragmentariness seem to predominate in the wholesale dispersion with which subjects, things and habits coexist, characterized by boundaries which are transparent and yet at times unreachable.

The various pieces in the mosaic of the contemporary city, their dimensions, reciprocal distance, the period of construction and the inhabitants all show us a city that has been chopped up into pieces. The contemporary city is the locus not only of complexity but also of simultaneity and instability, which give rise to situations of mutation and transitoriness. These are often predominantly motivated by economic gain, to the detriment of place identity which becomes increasingly compromised or unrecognizable.

For these reasons, liveability together with health and happiness, represent important factors to take into account in designing paces and spaces.

Urban happiness can be given by both the intangible aspects and perceptions and is strongly connected to architectures, public spaces and natural environment. Health is meant to be an important factor to both resolve diseases and to improve well-being. This can be supported by a suitable way to design places and public spaces. Liveability is related to a more general perception of beauty, quality and comfort of the place, although not necessarily in connection with the health. Urban health, liveability and happiness are three concepts that are interwoven and are strongly related to the sustainability and well-being of both people and place. To identify the presence of these three factors in a site and realize an urban project which contains these is a big challenge.

Accordingly, the article presented the theoretical framework related to the health, happiness and liveability in urban design and public spaces. Within this framework, the Ecoliv@ ble+ Design method was illustrated, through the case study of False Creek in Vancouver, Canada [30].

The case has been particularly emblematic because of the strong energies which the city is using to reach healthy and liveable place for all. False Creek has characteristics and facilities which make it a very comfortable place, which encourage its use for the many activities which offer, including taking a break. The particularly beautiful environment-composed of both sea and mountains_-give people the possibilities of doing many things, for many times 
and for long time, creating a satisfying experience which can be repeated daily. Furthermore, the perception of a safe place plays an important role for its health, liveability and happiness. Finally, the surveys and questionnaire demonstrate how a good urban design can be well perceived by people — both inhabitants and tourists — of different age, culture and habits and contribute to its success in terms of socialization, liveability and sustainability. The information collected by the internet websites — such as Tripadvisor and Booking — and the social networks — such as Facebook, Instagram and Twitter-confirm both the liveability, healthy and happy characteristics and the success of False Creek.

As further factors of success, in False Creek, the presence of the Olympic Village, the Science World and the Granville Island give to the area additional occasions of attraction, and, again, in many parts of False Creek there are sculptures of different types, which improve the perception of happiness often connected to the art.

The urban regeneration process of False Creek is still in progress, but, all the projects are designed with health and liveability factors as a priority, connecting these to sustainability and high quality design [29]. The attention to people and their needs was, in any case, observed in the project realized until now making it as an emblematic case of sustainable regeneration.

\section{REFERENCES}

[1] Sepe, M., Liveable and healthy city design. WIT Transactions on Ecology and the Environment, Vol. 217, eds. C.A. Brebbia, N. Marchetini \& G. Passerini, WIT Press, 2018, ISSN 1743-3541.

[2] Sepe, M., The role of public space to achieve urban happiness. International Journal of Sustainable Development and Planning, 2(4), pp. 724-733, 2017. https://doi. org/10.2495/sdp-v12-n4-724-733

[3] Friedmann, J. \& Douglass, M., Cities For Citizens: Planning and the Rise of Civil Society in a Global Age, Chichester, NY: John Wiley \& Sons, 1998.

[4] Carmona, M., Heath, T., Oc, T. \& Tiesdell, S., Public Places-Urban Spaces, Architectural Press: Oxford, 2010.

[5] Project for Public Spaces, How to Turn a Place Around: A Handbook for Creating Successful Public Spaces, Project for Public Places: New York City, NY, 2001.

[6] Sepe, M., Planning and place in the city. Mapping Place Identity, Routlege: London, New York, 2013.

[7] Lynch, K., The Image of the City, Mit Press: Cambridge, 1960.

[8] Appleyard, D., Liveable Streets, University of California Press: Berkeley, 1981.

[9] Montgomery, J., Making a city: urbanity, vitality and urban Design. Journal of Urban Design, 3, pp. 93-116, 1998.

[10] Porteous, J.D., Environmental and Behavior: Planning and Everyday Urban Life, Addison-Wesley: Massachusetts, 1977.

[11] Gehl, J., Cities for People, Island Press: Washington, 2010.

[12] Sepe, M., Preserving, reconstructing and enhancing the place identity: identifying principles of urban sustainability with PlaceMaker method. International Journal of Sustainable Development and Planning, 9(2), pp. 277-300, 2014. https://doi. org/10.2495/sdp-v9-n2-277-300

[13] Zelinka, A. \& Brennan, D., Safescape, Creating Safer, More Livable Communities Though Planning and Design, Planner Press APA: Chicago, 2001.

[14] Florida R., Mellander C. \& Rentfrow, P.J., The happiness of cities. Regional Studies, 47(4), pp. 613-627, 2013. https://doi.org/10.1080/00343404.2011.589830 
[15] Saunders, L., Healthy cities. Urban Design Group Journal, 142, pp. 12-39, 2017.

[16] McCay, L., Designing mental health into cities. Urban Design Group Journal, 142, pp. 25-27, 2017.

[17] Crappsley, R., Designing streets for good health: now and in the future. Urban Design Group Journal, 143, pp. 10-11, 2017.

[18] Taylor, A.F., Wiley, A., Kuo, F.E. \& Sullivan, W.C., Growing up in the inner city: Green spaces as places to grow, Environmental Behavior, 30(1), pp. 3-27, 1998. https://doi. org/10.1177/0013916598301001

[19] Zidansek, A., Sustainable development and happiness in nations. Energy, 32(6), pp. 891-897, 2007. https://doi.org/10.1016/j.energy.2006.09.016

[20] Montgomery, C., Happy City, Penguin: London, 2013.

[21] Burns, G.W., Naturally happy, naturally healthy: The role of natural environment in well-being. The Science of Well-Being, eds. F.A. Huppert, N. Baylis \& B. Keverne, Oxford University Press: New York, 2005.

[22] Ballas, D., What makes a 'happy city'? Cities, 32, pp. S39-S50, 2013. https://doi. org/10.1016/j.cities.2013.04.009

[23] Burns, G.W., Naturally happy, naturally healthy: The role of natural environment in well-being. The Science of Well-Being, eds. F.A. Huppert, N. Baylis \& B. Keverne, New York, NY: Oxford University Press, 2005.

[24] Burton, L., Mental well-being. The Routledge Handbook for Health and Well-Being, eds. H. Barton, S. Thompson, S. Burgess \& M. Grant, London: Routledge, 2015.

[25] Kyttä, M., Broberg, A., Haybatollahi, M. \& Schmidt-Thomé, K., Urban happiness: context-sensitive study of the social sustainability of urban settings. Environment and Planning B, 43(1), pp. 34-57, 2016. https://doi.org/10.1177/0265813515600121

[26] Sepe, M., Improving sustainable enhancement of cultural heritage: smart placemaking for experiential paths in Pompeii. International Journal of Sustainable Development and Planning, 10(5), pp. 713-733, 2015. https://doi.org/10.2495/sdp-v10-n5-713-733

[27] City of Vancouver, https://vancouver.ca (accessed 20 November 2018).

[28] Delgado, J.P., Waterfront: The Illustrated Maritime History of Greater Vancouver, Stanton Atkins, Dosil Publishers, Vancouver, 2010.

[29] Pyky, R., Neuvonen, M., Kangas, K., Ojala, A., Lanki, T., Borodulin, K. \& Tyrväinen, L., Individual and environmental factors associated with green exercise in urban and suburban areas. Health and Place, 55, pp. 20-28. (accessed 17 November 2018).

[30] Mathewson, D. \& Karaga, K., Vancouver as a benchmark. Urban Design Group Journal, 145, pp. 25-27, 2018. 